\title{
Natural Resources, Decentralization, and Risk Sharing: Can Resource Booms Unify Nations?*
}

\author{
Fidel PEREZ-Sebastian \\ U. Alicante and U. Hull
}

\author{
OHAD RAVEH ${ }^{\dagger}$ \\ Hebrew University of Jerusalem
}

January 2016

\begin{abstract}
Previous studies imply that a positive regional fiscal shock, such as a resource boom, strengthens the desire for separation. In this paper we present a new and opposite perspective. We construct a model of endogenous fiscal decentralization that builds on two key notions: a trade-off between risk sharing and heterogeneity, and a positive association between resource booms and risk. The model shows that a resource windfall causes the nation to centralize as a mechanism to either share risk and/or prevent local capture, depending on the relative bargaining power of the central and regional governments. We provide cross country empirical evidence for the main hypotheses, finding that resource booms: (i) decrease the level of fiscal decentralization with no U-shaped patterns, (ii) cause the former due to risk sharing incentives primarily when regional governments are relatively strong, and (iii) have no effect on political decentralization.
\end{abstract}

Keywords: Natural resources, decentralization, bargaining power, risk sharing, secession

JEL classification: H77, Q33

${ }^{*}$ Fidel Perez-Sebastian thanks the Spanish Ministry of Science and Technology (ECO2012-36719), Generalitat Valenciana (PROMETEO/2013/037), and the Instituto Valenciano de Investigaciones Económicas for financial support. We thank seminar participants at the Hebrew University of Jerusalem, University of Oxford, and the 2015 OxCarre-Oslo Workshop, as well as to Robin Boadway, Yaniv Reingewertz, Ragnar Torvik, Rick van der Ploeg, Tony Venables, and Wessel Vermeulen for helpful comments and suggestions.

${ }^{\dagger}$ Correspondence to: Ohad Raveh, Department of Environmental Economics and Management, and the Center for Agricultural Economic Research, Hebrew University of Jerusalem, Rehovot, Israel. Email: ohad.raveh@mail.huji.ac.il 


\section{Introduction}

The reasons behind why nations centralize or why regions demand higher levels of independence are of first order importance. One contributing factor might be the discovery of natural resources. A windfall of natural riches often provides an enormous source of income that leads to conflict over its distribution, and can even threaten the nation's unity. This paper tries to unfold this resources-unity nexus by addressing the following question: do resource booms affect the level of fiscal decentralization (henceforth, FD)? Contrary to conventional wisdom, we argue that resource booms may in fact contribute to the unification of nations, by leading to higher levels of government centralization.

Previous studies on the determinants of FD such as Arzaghi and Henderson (2005), Oates (1972), Panizza (1999) and Treisman (2006)) identify several key determinants, ranging from historical and geographical to cultural and institutional. However, very little attention has been devoted to the role that natural resources may have in this. ${ }^{1}$ This paper contributes to this strand of the literature by filling this gap and presenting new insights on the association between natural resources and decentralization.

The potential association between natural resources and FD has been observed in several occasions. "It's Scotland's Oil" was the widely publicized slogan used in the 1970s by the Scottish National Party to promote Scottish independence; as the slogan implies, the discovery of oil in the North Sea (within the territory of Scotland) created a struggle, between Scotland and the United Kingdom, on the fiscal control over the oil rents. A more extreme case is Sudan, which eventually split into two nations mainly due to the large oil reserves located in the south. Boadway (2006) discusses the influential role of resource booms in Canadian fiscal federalism; indeed, various agreements made between the provincial and federal governments of Canada regarding regional fiscal control over natural wealth provide an indication for that. Similarly, drawing on the related literature on natural resources and conflicts, various studies indirectly document the effects of resource booms on levels of fiscal control in developing nations such as Angola, Colombia, Iraq, Nigeria, and Sierra Leone, among others (see Ross (2004), (2006), and Blattman and Miguel (2010), for surveys).

Albeit not explicitly formalized, a similar correlation is suggested by previous models of endogenous FD. Arzaghi and Henderson (2005) and Panizza (1999), for instance, imply that a regional fiscal shock is expected to increase the level of FD, and strengthen the desire for separation. Ob-

\footnotetext{
${ }^{1}$ An exception is Freinkman and Plekhanov (2009), who find that resource rich Russian regions tend to have more centralized governments. Unlike these authors, we provide national-level, cross country empirical evidence that addresses potential endogeneity issues and is linked to a formal theory that emphasizes different mechanisms.
} 
served patterns may, however, hide other factors whose influence on decentralization demands is simply exacerbated by natural resources. For example, ethnic fractionalization is often the trigger for many secessionist conflicts. To illustrate this point notice that in the Scottish case we have the historical tension between the Scots and the Anglo-Saxons; and in Sudan, the Arabs in the north versus the Africans in the south.

We offer a theory and empirical evidence that point at the opposite direction; namely, that resource booms can lower the level of FD. The theory treats FD as an endogenous variable, and investigates how it might be affected by a windfall of natural resources, building on two main features: (i) a trade-off between risk sharing and heterogeneity, and (ii) a positive association between resources and risk. The heterogeneity assumption follows Panizza (1999), and is a consequence of spatial decay of public goods' efficiency. In turn, the positive association between resource wealth and volatility has been widely discussed in previous studies (e.g. Poelhekke and Van der Ploeg (2009)). Furthermore, as Figure 1 illustrates, this relationship is also a feature of our sample, showing a positive correlation between the share of oil rents in GDP and the standard deviation in the growth of real GDP per capita $(\rho=0.74) .^{2}$

Focusing on cases where regional demands matter, risk sharing is the main mechanism put forward by our theory. ${ }^{3}$ In the model, we consider two sources of risk: revenue volatility, and local inefficiency. The first is based on several studies documenting excessive volatility in oil prices (Blattman et al. (2007), and Davis et al. (2001)), and the incentive this provides for governments to share the risk involved (Stroebel and Benthem (2013)). The second is motivated by the notion that resource dependence may create adverse effects such as corruption and other development-inhibiting risks that fall under the so-called natural resource curse hypothesis. ${ }^{4}$ Importantly, these effects can also provide resource rich regional governments an incentive to mitigate them through sharing. Indeed, recent studies indicate that resource-booming local governments are able to mitigate the adverse effects of resources, and even grow on the account of their neighboring resource poor regions, in fiscally decentralized and federalized economies (Beine et al. (2014), Cai and Treisman (2005), Papyrakis and Raveh (2014), and Raveh (2013)).

In the model, the central and regional governments (henceforth, CG and RG, respectively) have different incentives regarding FD. In particular, if the former does not care about the latter's

\footnotetext{
${ }^{2}$ In the empirical part we describe these variables and discuss the sample in detail.

${ }^{3}$ Previous secession models such as Bolton and Roland (1997), and Buchanan and Faith (1987) focus as well on regional demands. We substantiate this point further in the empirical part.

${ }^{4}$ The natural resource curse hypothesis describes an inverse relationship between natural resource abundance and long-term economic growth; see Van der Ploeg (2011) for a review of the literature. Within this literature, PerezSebastian and Raveh (2015) show that FD can help explain the resource curse finding, but do not study the effect of natural resources on FD.
} 
welfare, it would prefer full centralization regardless of the amount of natural riches - being the standard result in the literature. The FD trade-off is at work only if RG has some bargaining power and, as a consequence, CG decides to account for RG's preferences when determining the equilibrium level of FD. Under these circumstances, in which regional demands are taken seriously, the model shows that a resource boom can lead to more centralization due to either the incentive that CG has to reduce the impact of regional officials' rent-extraction behavior and/or the RG's desire to share the risks involved across the nation. The risk sharing mechanism becomes relatively more important as RG's bargaining power rises.

In the empirical exercise, we motivate our focus on FD (as opposed to political decentralization), and test the model's main predictions, including the hypothesized association between resource booms and FD. For that, we employ a large panel of countries, spanning over several decades, and use the Kearney Decentralization Index (Arzaghi and Henderson (2005)), and the World Bank's Vertical Imbalance measure, to approach the endogenous variable. Since the Kearney index is discrete in nature, probit estimation techniques are used, along with linear methods. As a measure of resource abundance, we employ several proxies. The first is GDP share of oil rents, which is suggested by the model. The other measures are chosen so as to address possible endogeneity issues; these include stock measures of giant oil fields, and price-based measures that exploit exogenous variations in the price of crude oil. The main analyses, as well as several robustness checks that test different controls and time periods, indicate that resource booms negatively affect FD (with no apparent U-shaped effects), and have no impact on political decentralization.

In addition, we also test the risk sharing mechanism proposed by the model, and compare it against other potential channels. For this, we use a standard volatility proxy: the standard deviation in the growth of real GDP per capita. While each of the additional potential channels that we test do not affect the impact of resources, the risk proxy does. When added to the regressions, the effect of resources on FD vanishes, that is, their impact -net of risk- becomes statistically insignificant and with substantially lower magnitude; moreover, consistent with the predictions of the model, we find this result is primarily driven by cases where RGs have some relatively significant bargaining power, as opposed to when CG is relatively stronger where resource booms decrease FD irrespective of risk. Importantly, we observe the former cases apply to a major portion of our sample. Last, based on the assumption that local inefficiency worsens with weaker institutions, we test for the relative dominance of the revenue volatility and local inefficiency effects by adding an interaction term of our proxies for institutional quality and resources. As the relevant coefficient is not precisely estimated, we conclude that although both effects may incentivize risk sharing, it is the revenue volatility effect that appears to be the larger contributor. 
Besides the literature on the determinants of decentralization, our work is also related to papers on the importance of volatility in resource extraction and management, which include Poelhekke and Van der Ploeg (2009, 2010), Van den Bremer and Van der Ploeg (2013), Van der Ploeg (2010) and Stroebel and Benthem (2013). None of them focus on government decentralization. Several authors such as Persson and Tabellini (1996a, 1996b) analyze fiscal transfers among regions as a way to share risk; unlike them, we allow for different levels of decentralization including the possibility of secession, and look into the consequences of resource booms. The paper is as well related to the literature on secession and the endogenous size of nations, including Alesina and Spolaore (1997), Bolton and Roland (1997), and Buchanan and Faith (1987). As Alesina and Spolaore (2005) argue in their survey, the basic trade-off in this literature is between preference heterogeneity and efficiency in the provision of public goods. Our main trade-off, instead, is between preference heterogeneity and risk sharing, with applicability to the case of natural resource discoveries.

The paper is structured as follows. Section 2 presents the theoretical analysis. Section 3 carries out the empirical work. Section 4 summarizes our main findings and offers concluding remarks.

\section{A Model of Natural Resources and Fiscal Decentralization}

We build a model similar to Arzaghi and Henderson's (2005). Our framework, however, proposes an alternative trade-off tightly linked to natural resources, and can account for partial decentralization. The exploitation of natural riches is subject to revenue volatility that harms the economy due to risk aversion. In addition, central and regional governments may face different costs associated with the exploitation of natural resources. Both revenue volatility and local inefficiency increase with the stock of natural capital. Under these circumstances, the endogenous level of decentralization can diminish after a resource windfall. At the end of the section we discuss the robustness of the results to alternative assumptions.

\subsection{The environment}

The economy is composed of two regions: region 1 hosts the central government (CG); region 2 has natural resources and a regional authority $(\mathrm{RG})$. FD means that RG is allowed to keep a fraction of the taxes and natural resource rents collected in the area to partially finance public goods. If region 2 obtains a relatively larger fraction then the economy is more fiscally decentralized. As in Arzaghi and Henderson (2005), we assume for simplicity that the constitution forces to charge the same income tax rate $(\tau)$ and enjoy the same level of public goods per capita $(g)$ in all regions within the union. 
Region $j$ is populated by $L_{j}$ inhabitants, with $L_{1}>L_{2} \cdot{ }^{5}$ Each risk averse individual in a region receives an amount of non-natural-resource income equal to $y_{j}$. People's preferences are given by:

$$
u=\left(x^{\alpha} g^{1-\alpha}\right)^{\theta}
$$

where $x$ is the per capita level of private good consumption. The parameters $\alpha, \theta \in(0,1)$, where $\theta$ captures the degree of risk aversion.

A fraction of taxes and resource rents are collected by $\mathrm{CG}$ and the rest by RG. The amount collected by RG serves to finance, at the local level, a fraction $\mu$ of the public good, and the rest is supplied by the central authority. Following Panizza (1999), there is spatial decay associated to CG's provision of the public good to RG. This can be regarded as having a preference for heterogeneity (i.e. putting larger weight on the local public goods), or simply as a cost for delivering public goods to a distant region; in either case, this guarantees that RG will demand some degree of decentralization, even in the absence of natural resources. Thus, the amount of public goods measured in efficiency units in region 2 equals $[(1-\mu)(1-\delta)+\mu] g$, or $[1-\delta(1-\mu)] g$; where $\delta$ is the spatial decay parameter, and $\delta, \mu \in[0,1]$. Clearly, in region $1, \mathrm{CG}$ will supply all the public goods and collect all taxes.

The above information implies that we can write (1) as:

$$
u_{1}=\left[y_{1}^{\alpha}(1-\tau)^{\alpha} g^{1-\alpha}\right]^{\theta}
$$

and

$$
u_{2}=\left[y_{2}^{\alpha}(1-\tau)^{\alpha}[1-\delta(1-\mu)]^{1-\alpha} g^{1-\alpha}\right]^{\theta}
$$

for regions 1 and 2, respectively.

Revenues net of direct and indirect costs from the exploitation of natural resources equal $Z(1-$ $b \mu$ ). The variable $Z$ is random, subject to relatively large fluctuations due to changes in the price of minerals (as documented by Davis et al. (2001), for instance). Consistent with the evidence on the said natural resource curse, a fraction $b \mu$ of potential revenue is lost due to moral hazard and corruption problems; because this amount is captured by local officials, we refer to $Z b \mu$ as local capture. Notice that the chosen formalization, via the negative impact of $\mu$ on revenues, underlines two assumptions: first, it supposes these adverse effects affect RG more strongly than CG; second, it suggests that FD raises corruption in natural resource abundant regions.

Let us elaborate on these last two suppositions. Starting with the first, while it may be a

\footnotetext{
${ }^{5}$ Although we consider two regions for simplicity, one can think of a setup with $\mathrm{N}$ regions, where CG is an amalgamation of the N-1 resource poor ones. With this framework in mind, we find this relative-size assumption applicable.
} 
consequence of RG's smaller size ${ }^{6}$ it may also be triggered by additional sources. For instance, Wilson (1966) argues that state-level politics are more prone to corruption because state capitals are far away from the main metropolitan areas and, as a consequence, face less scrutiny by citizens and the media. Along the same lines, Prud'homme (1995) believes that there are more opportunities for corruption at the local level, because local officials usually have more discretionary powers than national decision makers, and because local authorities are likely to be more subject to pressing demands from local interest groups. More recently, Bardhan (2002), Bardhan and Mookherjee (2000), and Brosio (2006) also argue that the lower the level of government the less the capacity to control costs and the higher the degree of corruption, especially in developing nations.

Importantly, the assumption also obtains empirical support in the data. Using wide samples of nations, Goldsmith (1999) and Treisman (2000) find that states with more tiers of government have, on average, higher perceived corruption. Campante and Do (2014) show that isolation is related to more corruption. In particular, using data in U.S. states, they find that isolated capital cities are robustly associated with greater corruption levels because isolation weakens accountability mechanisms such as newspapers coverage. Their result is important for our purposes because natural resources are located, on average, in low density and isolated areas (e.g., see Perez-Sebastian and Raveh (2015)). Other papers, like Glaeser and Saks (2006), obtain evidence that states are more prone to corruption than the central government. More specifically, employing federal corruption convictions, they find that corruption in U.S. states increases with the fraction of government employment that is related to local government employees, but falls with the share of state government workers.

Moving to the second supposition, evidence suggest that decentralization increases corruption when linked to fiscal windfalls that are taken as given by local authorities - a particular case being revenues from natural resources- because it can facilitate capture of local governments, and collusion between officers and elites at the local level. ${ }^{7}$ For example, Caselli and Michaels (2013) find that in Brazil, a fiscally decentralized nation, municipalities that enjoy an oil-based fiscal windfall become more corrupted. Galasso and Ravallion (2005) test the hypothesis put forward by Bardhan and Mookherjee (2000) that the case for decentralization of poverty reduction programs critically depends on the extent of local program capture by the elites. They find evidence of substantial local elite capture within the Food for Education program in Bangladesh. Similar evidence is found by Araujo et al. (2008) for a social development fund in Ecuador. Jia and Nie (2015) show that decen-

\footnotetext{
${ }^{6}$ Being the smaller economy, a resource windfall will take a larger share in RG's GSP than in CG's, hence making RG relatively more susceptible to the adverse effects of resources, compared to CG, given an equivalent windfall.

${ }^{7}$ This does not imply that, in general, FD increases corruption. The empirical evidence on this is not conclusive. See, for example, Lambsdorff (2005), and Mookherjee (2015) for reviews of the literature, and Brennan and Buchanan (1980) and Seabright (1996) for views stressing that FD should rather diminish the extent of corruption.
} 
tralization in China has facilitated collusion between coal mines and industry regulators. Duek and Rusli (2010) provide evidence that decentralization policies that have granted more authority to Indonesian states to generate higher own revenues from natural resources have led to wider spread of corruption. Last, results in Brollo et al. (2012) and Fisman and Gatti (2002) strongly support that FD in the form of fiscal windfalls has raised corruption levels in Brazilian municipalities and U.S. states, respectively.

An additional key assumption, consistent as well with evidence mentioned previously, is that resource windfalls increase risk. Specifically, both the revenue volatility and the local inefficiency effects increase with $Z$. The former occurs because we suppose that the variance of $Z$-denoted by $\sigma_{z}^{2}$ - rises with the stock of natural resources (later we discuss an example in detail), and the latter because the cost of the inefficiency equals $Z b \mu$. In addition, we abstract from making any specific assumptions on the distribution of resource rents apart from considering extreme scenarios in which either CG or RG fully control $Z$. The reason is that, within the union, the government that controls the resource rents can impact the equilibrium outcome only through its effect on bargaining power.

Finally, the interpretation of $Z$ deserves some comment. Although referred to as a measure of rents, $Z$ can be regarded more generally as a measure of the resource sector, or a measure of resource dependence. Nevertheless, all these alternative interpretations deliver a $Z$ that remains susceptible to the risk involved with a resource windfall. The option to consider a more general view that may include such interpretations will prove useful in our discussion on volatility and its potential effects.

Given the above information, we can write the budget constraint for the union as:

$$
\tau L_{1} y_{1}+\tau L_{2} y_{2}+Z(1-b \mu)=\left(L_{1}+L_{2}\right) g
$$

and for region 2 , if it becomes an independent nation, as: ${ }^{8}$

$$
\tau L_{2} y_{2}+Z(1-b \mu)=L_{2} g
$$

We consider a two-stage political scenario. In the first stage, before the price of minerals is known, CG and RG are elected democratically by the inhabitants of the whole country and the ones of region 2 , respectively. ${ }^{9}$ At that time, a decision of whether or not to pursue a secession

\footnotetext{
${ }^{8}$ The one-period budget constraints (4) and (5) must always hold. This is clearly a simplification of the model. Considering an intertemporal budget constraint could have been more appropriate for addressing a wider set of issues; however, since allowing governments to borrow should not have any qualitative impact on our main results, we follow the simplifying setting.

${ }^{9}$ This framework follows Hatfield and Miquel (2012), and is used primarily for convenience. Main results would
} 
attempt must also be made by RG. In the second stage, the state of nature (i.e., the price, and consequently the value of $Z$ ) is revealed; governments then decide fiscal policy by choosing the levels of $\mu, g$, and $\tau$. If $\mathrm{CG}$ and RG belong to the same union, fiscal policy is decided by the stronger CG who assigns an exogenous weight to RG's preferences based on equalization schemes driven by the region's relative population size. The bargaining power of RG in this context comes from the constraint imposed on CG's decision by the probability that the secession attempt succeeds. These simplifying assumptions, motivated by some of the anecdotes discussed initially, will allow to obtain clean results that will later guide the empirical exercise on the main mechanisms that drive the effect of natural resources on FD.

\subsection{Preliminary analysis}

For the ease of exposition, we first derive some useful results, and thereafter turn to the analysis of the two-stage game. Specifically, we look into the separate cases of Independence and Union to illustrate the potential costs of benefits of resource rents within our framework, and their effect on the FD trade-off.

\subsubsection{Independence}

We start by examining the case where the two regions are independent states. Denote $u_{j}^{I}$ the utility obtained in this scenario by region $j$, where $I$ stands for independence. Natural resources would be fully controlled by region 2 where they are located. Both countries would face very similar problems, determining the level of government spending only. For concreteness, let us focus on region 2. Substituting equality (5) into objective function (3) for $\mu=1$ and $\delta=0$, we get that the value of $g$ is chosen such that:

$$
\max _{g}\left\{u_{2}^{I}=\left[y_{2}^{\alpha}\left(1-\frac{L_{2} g-Z(1-b)}{L_{2} y_{2}}\right)^{\alpha} g^{1-\alpha}\right]^{\theta}\right\} .
$$

The level of public goods that solves this maximization problem is:

$$
g=(1-\alpha)\left[\frac{L_{2} y_{2}+Z(1-b)}{L_{2}}\right] .
$$

That is, the level of public good provision is a fraction - given by the weight of $g$ in the utility function- of total income net of the amount of local capture $Z b$. The parameter $b$ appears in the

not change if other regimes are considered, as long as CG represents the interest of the resource poor regions. Albeit being interesting, we consider the case where $\mathrm{CG}$ is controlled by the resource rich region as a rare scenario beyond the scope of this work. In addition, we abstract from making any further specific assumptions on the quality of institutions. As will be evident in the empirical part, institutional quality does not seem to play a key role in this. 
last two expressions because of the larger tax rate needed to finance a given level of the public good due to corruption. Arguably, RG might not care about it since gains of those that benefit from corruption may offset the losses; we argue in section 2.5 that explicitly considering this rent-seeking behavior should not affect our results.

RG's level of welfare under independence is obtained by substituting solution (7) into problem (6)'s objective function; which delivers:

$$
u_{2}^{I}=\left\{\alpha^{\alpha}(1-\alpha)^{1-\alpha}\left[\frac{L_{2} y_{2}+Z(1-b)}{L_{2}}\right]\right\}^{\theta}
$$

The value of $u_{2}^{I}$ then depends on per capita net income from resource and non-resource sources, the weights of the two consumption goods in the utility function, and the rate of risk aversion.

\subsubsection{Union}

Next, we derive some of the basic results if the two states are within a union. First, use budget constraint (4) to solve for the tax rate necessary to finance a given level of $g$. We obtain

$$
\tau=\frac{L g-Z(1-b \mu)}{Y}
$$

where $Y=L_{1} y_{1}+L_{2} y_{2}$, and $L=L_{1}+L_{2}$. Expression (9) takes into account that both $\tau$ and $g$ need to be the same in the two regions.

The union's problem is determining fiscal policy. CG, which represents region 1's median voter given that $L_{1}>L_{2}$, is the one that makes the decision. It is straightforward that, due to their different preferences, the two governments have different optimal decentralization levels; each government seeks to get as close as possible to its median voter's preferred fiscal policy. We assume that CG takes into account RG's preferences when making the decision, based on its relative population size. Hence, defining $\xi=L_{1} / L$, we can think of the optimal solution as the outcome of the following maximization problem:

$$
\max _{\mu, g}\left\{\xi u_{1}^{D}+(1-\xi) u_{2}^{D}\right\}
$$

In problem (10), functions $u_{1}^{D}$ and $u_{2}^{D}$ denote utility for region 1 and 2 , respectively, when they belong to the union. More specifically, substituting (9) into preferences (2) and (3) yield:

$$
u_{1}^{D}=\left[y_{1}^{\alpha}\left(1-\frac{L g-Z(1-b \mu)}{Y}\right)^{\alpha} g^{1-\alpha}\right]^{\theta}
$$




$$
u_{2}^{D}=\left[y_{2}^{\alpha}\left(1-\frac{L g-Z(1-b \mu)}{Y}\right)^{\alpha}[1-\delta(1-\mu)]^{1-\alpha} g^{1-\alpha}\right]^{\theta} .
$$

Notice that even if RG does not internalize the consequences of its officials' corruption (the cost $Z b \mu$ ), the government that decides, CG, wants to take them into account because those losses hurt region 1.

The FOC to problem (10) with respect to $g$ provides the optimal amount of public goods as:

$$
g=(1-\alpha)\left[\frac{Y+Z(1-b \mu)}{L}\right]
$$

As above, investment in public goods equals a constant fraction of total per capita rents. The largest possible level of $g$ is achieved when $\mu$ equals zero.

Using (13) we can derive RG's indirect utility within the union as a function of $\mu$. This is obtained by combining optimality condition (13) and expression (12):

$$
u_{2}^{D}(\mu)=\left\{\left[y_{2} \alpha \frac{Y+Z(1-b \mu)}{Y}\right]^{\alpha}\left[(1-\delta+\delta \mu)(1-\alpha) \frac{Y+Z(1-b \mu)}{L}\right]^{1-\alpha}\right\}^{\theta}
$$

or rewriting it,

$$
u_{2}^{D}(\mu)=\left\{\left(\alpha \frac{y_{2}}{Y / L}\right)^{\alpha}[(1-\alpha)(1-\delta+\delta \mu)]^{1-\alpha}\left[\frac{Y+Z(1-b \mu)}{L}\right]\right\}^{\theta} .
$$

Function (14) displays an inverted U-shape provided that the ratio of output to resource rents is sufficiently large, and in particular, $Y / Z>(1-\delta) b /[(1-\alpha) \delta]-1$. Under this assumption, the decrease in the spatial decay inefficiency due to additional units of $g$ being supplied by RG dominates for low levels of FD, whereas the higher costs related to a larger $\mu$ dominates when FD is sufficiently high. Below, we use this expression to obtain the optimal level of decentralization.

\subsection{Stage 1: RG's perspective}

Armed with the above, we now start advancing towards deriving the equilibrium level of FD in the two-stage game. As mentioned, this begins with RG's decision on whether to become independent. Independence represents a more important decision than fiscal policy: it is relatively permanent, and may even need a modification of the constitution. For this reason, we assume that this decision is made before the state of nature is known, at the time when RG is elected. In addition, there is an exogenously-determined probability, denoted by $\varepsilon$, that the secession attempt succeeds, depending on the relative strength of the two governments; thus, $\varepsilon$ represents RG's relative power. ${ }^{10}$ For this

\footnotetext{
${ }^{10}$ The exogenous nature of this parameter is assumed for simplicity. We think of its value as being influenced by deep determinants of the probability that the region can become independent. They would include the military power
} 
probability to influence the first-stage outcome CG needs to impose a penalty on RG if the attempt ends up being a failure; for simplicity, we assume that if that is the case the payoff that RG receives equals zero.

Stage one provides RG's minimum acceptable level of $\mu$, denote it $\hat{\mu}$. Given the threat of independence, CG would later need to offer a level of $\mu$ equal or larger than the one that makes RG indifferent between staying and leaving the union. This indifference condition must hold in expected terms; that is,

$$
E\left[\varepsilon u_{2}^{I}\right]=E\left[u_{2}^{D}(\hat{\mu})\right]
$$

From expressions (8) and (14), this implies that:

$$
\varepsilon E\left[\left(\frac{L_{2} y_{2}+Z(1-b)}{L_{2}}\right)^{\theta}\right]=\left\{[1-\delta(1-\hat{\mu})]^{1-\alpha}\left(\frac{y_{2}}{Y / L}\right)^{\alpha}\right\}^{\theta} E\left[\left(\frac{Y+Z(1-b \hat{\mu})}{L}\right)^{\theta}\right] .
$$

Suppose that there is a resource discovery. The question is how $\hat{\mu}$ will change in expression (15), assuming that $\hat{\mu}$ takes on a value to the left of the one that maximizes the RHS (otherwise, $\hat{\mu}$ would not change). Effects can go in both directions. On the one hand, independence implies that the new resources are split among less people $\left(\triangle Z / L_{2}>\triangle Z / L\right)$, causing a reduction in the tax rate and an increase in the provision of public goods - call it the mean effect. On the other hand, the discovery increases uncertainty, and risk averse agents value that the union represents a larger economy, more able to diversify risks and diminish the incidence of revenue volatility on the tax rate and public goods. The impact of local inefficiency shows up as well in condition (15): net revenues from natural resources will be smaller and, as a consequence, the tax burden necessary to finance a given level of public goods will be larger if region 2 becomes independent $(1-b<1-b \hat{\mu})$. The mean effect then pushes towards independence, whereas the local inefficiency and revenue volatility effects call for a decline in the level of $\hat{\mu}$ as $Z$ rises. Hence, depending on parameter values, RG's risk-sharing and corruption-minimizing incentives can dominate RG's incentives to consume its own resource wealth.

To see the importance of volatility, and how it can lead to a reduction in $\hat{\mu}$, let us assume that resource rents $Z$ equals $p N$; where the variables $N$ and $p$ represent the constant flow and the random price of natural resources, respectively. The variable $p$ is distributed with mean $\bar{p}$ and variance $\sigma^{2}$. Clearly, the variance of $Z$ equals $N^{2} \sigma^{2}$, which increases with $N$. Let us also approximate the terms inside the expectation operator in both sides of expression (15) employing a second-order Taylor expansion around the mean.

of both sides, as well as cultural and ethnic differences, among others. The level of FD is, on the contrary, considered endogenous in the model; the main reason is that it represents the central theme in the analysis. 
The new definition of $Z$ implies that the expectation located in the RHS of (15) can be approximated as:

$$
E\left[\left(\frac{Y+Z(1-b \hat{\mu})}{L}\right)^{\theta}\right] \approx\left[\frac{Y+\bar{p} N(1-b \hat{\mu})}{L}\right]^{\theta}\left[1-\frac{\theta(1-\theta) \sigma^{2}}{\left(\frac{1}{1-b \hat{\mu}} \frac{Y}{N}+\bar{p}\right)^{2}}\right]
$$

In the RHS of this last expression, the terms in the first and second squared brackets provide the positive mean effect and the negative volatility effect of an increase in the stock of $N$, respectively. We see that the negative volatility effect rises with $N / Y$, that is, with the resource-output ratio. From this result, it is easy to deduce that, in the case of $\mathrm{RG}$, the relevant ratio that determines the impact of increasing volatility will be $N / L_{2} y_{2}$ (see next expression). Therefore, the fall in expected utility caused by the increase in volatility will be larger for an independent RG than under the union. This is the driving force behind the result presented in the next paragraph.

Performing the approximation of the term inside the other expectation operator and using (16), we can turn (15) into:

$$
\varepsilon\left[\frac{Y+(1-b \hat{\mu}) \bar{p} N}{L_{2} y_{2}+(1-b) \bar{p} N}\right]^{2-\theta}=\frac{\left\{[1-\delta(1-\hat{\mu})]^{1-\alpha}\left(\frac{y_{2}}{Y / L}\right)^{\alpha}\right\}^{\theta}}{\left(\frac{L}{L_{2}}\right)^{\theta}\left(\frac{1-b}{1-b \hat{\mu}}\right)^{2}} \frac{\left[\frac{Y}{(1-b \hat{\mu}) N}+\bar{p}\right]^{2}-\theta(1-\theta) \sigma^{2}}{\left[\frac{L_{2} y_{2}}{(1-b) N}+\bar{p}\right]^{2}-\theta(1-\theta) \sigma^{2}} .
$$

The LHS of (17) always declines with $N$. The RHS, on the other hand, can go up or down depending on whether the variance $\sigma^{2}$ is sufficiently large compared to the mean $\bar{p}$. For example, if $\bar{p}$ equals zero then it is easy to show that the RHS will go up with $N$, provided that $Y /(1-b \hat{\mu})>L_{2} y_{2} /(1-b)$. As a consequence, for a sufficiently small $\bar{p}$ and a sufficiently high ratio $Y / y_{2}$, the negative volatility effect will dominate and CG will be able to impose a smaller level of FD after a natural resource windfall.

What about the effect of a change in the probability of a successful secession attempt? If $\varepsilon$ falls, it is easy to deduce from (15) that the value of $\hat{\mu}$ that equalizes both sides of the expression will be smaller (again, assuming that $\hat{\mu}$ is to the left of the RHS maximum). Given that the probability that a secession attempt succeeds depends on the relative strength of the two players, we can conclude that a stronger RG will demand a larger minimum decentralization level.

The above exercise, hence, illustrates how RG may have an incentive to centralize following a resource boom, based on risk sharing motives. It also points out the importance of RG's relative bargaining power: the stronger CG is, the lower would be RG's minimum acceptable FD level; notice that as $\varepsilon$ approaches zero, so does $\hat{\mu}$. Having established $\hat{\mu}$, we next turn to discuss the next phase. 


\subsection{Stage 2: Equilibrium level of FD}

Stage 1 determined the minimum value of $\mu$ that $R G$ is willing to accept. At the beginning of stage 2 , the value of $Z$ (or $p$ if we follow the example given above) is revealed. CG takes this into account to determine the equilibrium level of FD. As explained, this process may factor in various issues that range from a simple agreement to past unsuccessful secession attempts or local riots, which we assume eventually conclude in some form of cooperation that maintains the union. ${ }^{11}$

Thus, CG solves problem (10) subject to $\mu \geq \hat{\mu}$. Substituting (13) into the FOC with respect to $\mu$ gives the optimal level of FD when $\mu>\hat{\mu}$ as a solution to the following implicit function:

$$
\frac{\xi[1-\delta(1-\mu)]^{1-(1-\alpha) \theta}}{(1-\xi) \delta(2-\alpha)}\left(\frac{y_{1}}{y_{2}}\right)^{\alpha \theta}+\mu=\frac{1}{2-\alpha}\left[\frac{1-\alpha}{b}\left(\frac{Y}{Z}+1\right)-\frac{1-\delta}{\delta}\right] .
$$

It can be easily proven that the optimal $\mu$ in the interior solution decreases with the ratio of natural rents to output $(Z / Y)$, a measure that we will exploit in the empirical part.

To elaborate on CG's perspective, we note that it seeks full centralization, as per the standard result in the literature. This is observed through $\xi$, CG's relative population size; for a sufficiently large value of it, $\mu$ becomes zero. ${ }^{12}$ The incentive with respect to natural resources relates to the amount of local capture $(Z b \mu)$, which $\mathrm{CG}$ internalizes given that the amount of taxes necessary to cover a given $g$ increases with it. In effect, it brings a cost to CG, incentivizing it to centralize. In the following section we discuss further potential interpretations of this.

An important issue is whether the equilibrium $\mu$ is going to be binding. If it is, then $\mu$ will equal $\hat{\mu}$, and as we have learned in stage 1 , RG's perspective will dominate - that is, risk sharing will be the main force behind the negative reaction of $\mu$ as a consequence of a natural resource boom. If on the other hand, the solution is interior, CG's perspective will be the one behind this negative impact, and risk sharing will play no role.

The key to the last issue is the relative strength of RG. Put differently, the latter insight reduces in our model to the probability that RG can succeed in a secession attempt. If $\varepsilon$ is sufficiently small, $\hat{\mu}$ will also be sufficiently low and the constraint on the value of $\mu$ will not be binding; conversely, if $\varepsilon$ is sufficiently large, the constraint will be binding. Therefore, the conclusion is that, only when RG is sufficiently strong, risk sharing becomes an important determinant of the degree of FD; otherwise, CG's desire to lower FD is the main driving force, under which risk sharing does

\footnotetext{
${ }^{11}$ This, in turn, means that while independence is a possibility in the model, we focus on examining the union-based outcomes. A corollary is that, as will be evident, in equilibrium a secession never occurs.

${ }^{12}$ A corollary to the above is that local inefficiency in the model guarantees that an equilibrium with $\mu \in(0,1)$ exists. Without this inefficiency, neither CG nor RG would experience any cost from FD. Hence, CG would be indifferent about the value of $\mu$, and RG would always prefer either $\mu=1$ or independence. Under these circumstances, revenue volatility would only contribute to the decision of choosing between $\mu=1$ and independence.
} 
not play a role. These empirical predictions will be taken to the data in the next section.

\subsection{Discussion}

Let us recap the main insights of the model. Provided RG has at least some bargaining power and that the negative local inefficiency and volatility effects are sufficiently dominant, we learn that the level of FD is a monotonically decreasing function of resource dependence, and that the importance of risk sharing in the determination of the level of FD increases with RG's relative bargaining power. In the empirical part we take these predictions to the data.

First, however, we dig deeper into the robustness of these theoretical results. In particular, we next elaborate on some of the model's main assumptions, its sensitivity to a change in them, and to the addition of new ones considered by previous literature. Specifically, concerning the latter point, we consider the option of adding rent-seeking politicians to the model, and we discuss the relation of a key assumption derived from the related literature on the endogenous size of nations to our framework.

In our framework, two fundamental assumptions trigger the above results: the first is that CG represents the larger economy, and the second is that corruption hits RG more strongly when interacted with resource booms. We note that neither is crucial to the analysis independently; it is sufficient that just one of them holds to derive the key results. This is true for both RG's and CG's perspectives. Starting with the former, RG prefers some centralization following a resource boom to share the risk of revenue volatility and local inefficiency; the first occurs through the cross-region size differences, and the second through the cross-region corruption-sensitivity differences. Having one of them is sufficient for incentivising RG to centralize. We, however, emphasized the volatility effect because it is not clear whether in reality RG would try to control its own corruption, and also because we show below that rent-seeking policymakers in RG could also prefer less FD when facing increasing volatility.

As for CG, while within our framework its incentives to centralize depend primarily on the crossregion corruption-sensitivity differences and the costs it bears on FD, some simple modifications can lead to similar results under different triggering factors, making the one we preferred emphasizing in the model not crucial for CG. For instance, it may well be that CG simply seeks to maximize its income following a resource boom and hence advances centralization, or that otherwise it seeks to centralize regardless of natural resources, as per the standard result in previous FD models. Another way to observe this is if we consider a more political-based point of view, as we do below.

Let us next modify our basic setup introducing rent-seeking politicians, a view that may be more applicable for developing nations which take an integral part in our analysis. Thus, define 
$R$ as the rents that politicians in region 2 extract, and equalize the parameter $b$ to zero; notice that the new scenario amounts to endogenizing the amount of local capture. The budget constraint implies that the tax rate needed to finance a given amount of public goods will then be given by:

$$
\tau=1-\frac{R+L g-Z}{Y} .
$$

Rents harm the union because they increase the tax rate. As long as rents are treated as a normal good in the utility function, $R$ will grow with local government's revenues, that is, with the level of FD times $Z$. As a consequence, even if CG also behaves as a rent seeker, it will still want to restrict RG-politicians' extraction capacity to increase its own income, by diminishing $\mu$. In addition, government officials' rents will also be affected by revenue volatility from natural resources, and as before, volatility will increase if there is a natural resource windfall, thus decreasing $\mu$ so long as rent seekers are sufficiently risk averse. The conclusion from this exercise is that a rent seeking behavior on the part of RG and/or CG should not have any significant effect on the results obtained in the theoretical analysis.

In the model we suppose that the weight $1-\xi$ that $\mathrm{CG}$ assigns to RG's preferences is population based, and hence does not depend on the current value of the secession-success probability $\varepsilon$ - our proxy for the RG's degree of power. Alternatively, we could consider a different interpertation of $\xi$ so that CG's relative strength affects both $\xi$ and $\varepsilon$, and that their values are negatively correlated. With this modification, where $\xi$ is no longer capped, the comparative static analysis related to a change in the bargaining power of the governments would become more tedious. In particular, in order for the equilibrium $\mu$ to be (not to be) binding when the RG (CG) is sufficiently strong, we would need that the effect of changes in the strength is sufficiently larger on $\varepsilon$ than on $\xi$. This might not be unreasonable, because the weight $\xi$ may depend as well on equalization schemes across regions, and therefore should tend to be more stable than the probability of becoming independent from the union.

An assumption that we do not consider but that is frequently employed in the literature on the optimal number of nations is Alesina and Spolaore's (1997): countries are formed by different regions to share the fixed costs associated to the provision of public goods. Alesina and Spolaore suppose that if a region wants to provide its own public goods then it needs to cover the whole fixed cost (call it $F$ ), so that it is multiplied by the number of providers. The implication is that the distance between regions needs to be sufficiently large to have more than one nation. Incorporating this assumption into our setup should not have a qualitative impact on our results. More specifically, having $F>0$ would require a sufficiently large degree of spatial decay in order to derive a positive optimal level of $\mu$; however, once the solution is interior, qualitative results would 
not vary because local inefficiency would still remain effective at determining $\mu$.

This conclusion could change, for example, if we instead incorporate into our model the following modified version of the fixed cost: we can consider that there is a fixed cost $F$ that CG needs to pay in order to provide $g$ (or a fraction of it) to the whole union; and that RG also needs to pay a fixed cost equal to $d$ times $\mu$, with $d>0$ and $d \mu \leq F$. In this scenario, even if we supposed that $b$ equals zero, some degree of FD would still be desirable due to the spatial decay of the services provided by public goods.

It can be shown that under the new premises:

$$
\tau=1-\frac{F+d \mu-Z(1-b \mu)+L g}{Y},
$$

and that the optimal level of decentralization when $\xi$ equals zero is given by:

$$
\mu=\frac{1}{2-\alpha}\left[(1-\alpha) \frac{Y+Z-F}{d+Z b}-\frac{1-\delta}{\delta}\right] .
$$

That is, a larger stock $Z$ of natural resources can now increase or decrease $\mu$. The variable $Z$ in the numerator captures that the fixed cost becomes relatively less important as the natural stock rises, pushing $\mu$ up. On the other hand, we have the local inefficiency effect in the denominator $(Z b)$ that pushes $\mu$ down. The final impact of $Z$ on $\mu$ will depend on parameter values. For our particular functional forms, a sufficient condition for the level of FD to fall with the stock of natural resources is that $(Y-F) b>d$.

The same is true for results in sub-section 2.3 under the said assumption. To understand this, notice that expression (17) would become:

$$
\varepsilon\left[\frac{Y+(1-b \hat{\mu}) \bar{p} N-F-d \hat{\mu}}{L_{2} y_{2}+(1-b) \bar{p} N-F}\right]^{2-\theta}=\frac{\left\{[1-\delta(1-\hat{\mu})]^{1-\alpha}\left(\frac{y_{2}}{Y / L}\right)^{\alpha}\right\}^{\theta}}{\left(\frac{L}{L_{2}}\right)^{\theta}\left(\frac{1-b}{1-b \hat{\mu}}\right)^{2}} \frac{\left[\frac{Y-F-d \hat{\mu}}{(1-b \hat{\mu}) N}+\bar{p}\right]^{2}-\theta(1-\theta) \sigma^{2}}{\left[\frac{L_{2} y_{2}-F}{(1-b) N}+\bar{p}\right]^{2}-\theta(1-\theta) \sigma^{2}} .
$$

This implies that $N$ affects both sides of the equality and $\hat{\mu}$ affects the LHS in the same way as in (17). However, the variation of $\hat{\mu}$ impacts the RHS differently, because now there is a component of the cost $(d \hat{\mu})$ borne by a fiscally decentralized economy that is independent of the natural stock. As a consequence, a resource windfall can generate a positive or negative variation on $\hat{\mu}$. Again, given our specific functional forms, it can be proven that if $(Y-F) b>d$ the negative volatility effect will dominate and CG will decrease $\hat{\mu}$ as a response to an increase in $N$ for a sufficiently small $\bar{p}$ and a sufficiently high ratio $Y / y_{2}$.

Last, another simplification in the model is that the levels of $g$ and $\tau$ are the same in all regions. 
Its main implication is that the distribution of $Z$ between regions within the union is irrelevant for the level of $g$. It has been made for tractability purposes. However, Raveh (2013) for example finds that within a union resource rich regions offer lower tax rates and greater public good provision compared to those offered by the resource poor ones. Applying this to the model would not provide further insights. The reason being that neither of the two main forces, namely the incentive of risk averse agents to reduce revenue volatility and the internalization of local inefficiency, would be qualitatively altered if $g$ and $\tau$ are not forced to be the same in both regions.

\section{Empirics}

The theoretical analysis revealed potential mechanisms for the effects of resource booms on the level of FD; however, to understand the direction and magnitude of these, as well as to further motivate some parts of our framework, we turn to the data. Hence, in this section we provide empirical evidence for the association between resource booms and decentralization. We first motivate our focus on FD -as opposed to political decentralization- and later investigate whether resource booms decrease the level of FD, as hypothesized in the theoretical analysis. We also try to shed light on the mechanisms pointed out by the model. In particular, we test whether the decrease in the degree of FD is driven by the risk sharing channel, and if this is applicable more specifically to nations with relatively stronger RGs. The Appendix describes in detail the countries and variables in each sample, including descriptive statistics.

\subsection{Decentralization and natural resources}

Resource booms may lead to changes in various aspects of decentralization, with the fiscal and political dimensions being the two key ones. We start by examining conditional correlations to better understand the patterns at hand. We employ a panel that covers the period 1970-1995 in 5 -year intervals, and includes 44 countries. ${ }^{13}$ The underlying model is the following:

$$
D_{i t}=\alpha_{0}+\alpha_{1} X_{i t}+\alpha_{2} R_{i, t-1}+\varphi_{i}+\eta_{t}+\varepsilon_{i t}
$$

where $D_{i t}$ is the decentralization level for country $i$ at time $t, X_{i t}$ is a vector of controls, $R_{i, t-1}$ is the resource proxy, and $\varphi_{i}$ and $\eta_{t}$ represent country and time fixed effects, respectively.

Previous studies on the determinants of decentralization have found that land area, income level, population size, institutional quality, and urbanization represent significant explanatory variables, each of them with a positive effect. ${ }^{14}$ Given these findings, we include them in the control vector,

\footnotetext{
${ }^{13}$ This is a maximized sample limited by the availability of data.

${ }^{14}$ See Arzaghi and Henderson (2005), Oates (1972), Panizza (1999), and Treisman (2006).
} 
with the exception of land area which has no time variation (and thus absorbed by the country fixed effects). In addition, we note the essential role of institutional quality in our case. In the model we abstract from making any specific assumptions on institutional quality; thus, including it in each of the specifications serves not only for maintaining consistency with the FD literature, but also for motivating our theoretical framework. In a later sub-section we present further robustness tests using this measure.

Variables in $X$ are measured as follows: ${ }^{15}$ institutional quality by the Political Rights Index (Freedom House); income level by the logarithm of real per capita GDP; population by total population; and urbanization by the share of urban population in total population. For the resource proxy, we start with the one suggested by the model in expressions (18) and (16): the GDP share of resource rents; in particular, the share of oil rents. We focus on oil because it represents a relatively large share of total resource rents. Oil has also a more exogenous nature compared to other types of resources, because oil-related operations are often managed by multinational firms that bring their own technology and production factors, making such operations largely independent of the country's development level. We test additional proxies in later sections.

The level of decentralization is captured by the Kearney Decentralization Index (Arzaghi and Henderson (2005)). Although there are other decentralization indices, we choose to employ this one primarily because it enables us to capture relative bargaining powers of CG and RG across countries, which takes an important role in the analysis. In addition, it covers a relatively large time period over a wide and heterogeneous sample that includes both developing and developed economies. Last, it allows us to use a balanced and complete panel, as opposed to other measures which present incomplete data. ${ }^{16}$ The Kearney index is comprehensive and covers nine distinct dimensions which touch on both the fiscal and political aspects of decentralization, namely: government structure, selection of regional executive, selection of local executive, override authority, revenue raising authority, revenue sharing, education authority, infrastructure authority, and police authority; in the Appendix we describe each in more detail. Two of these dimensions are directly related to FD: revenue raising authority, and revenue sharing; the remaining ones are concerned with more politically-oriented aspects. Each dimension is measured by a number between 0 and 4 , with 4 representing the highest level of decentralization and 0 the least.

Equation (23) is estimated for each of the nine dimensions and for the overall index, using OLS. Results appear in Regressions 1-9 of Table 1 for each of the components and the aggregated

\footnotetext{
${ }^{15}$ Unless specified otherwise, all data come from World Bank Development Indicators. See Appendix for more detailed information.

${ }^{16}$ For instance, in the World Bank's Fiscal Decentralization Indicators (a measure of FD that we adopt later for robustness tests), some countries have observations for only one or two time periods.
} 
index; the exception is the revenue raising authority dimension, because this one is the focus of our subsequent analysis, and the equivalent benchmark results for it are presented separately in Regressions 1 and 5 of Table 2. As can be seen, oil rents are negatively correlated with the two abovementioned fiscally-related dimensions, and have no significant association with the remaining politically-related ones. Moreover, there is also an apparent negative relationship with the overall index, which seems to be entirely driven by the correlation with the FD channels.

To better distinguish between the FD-related and non-FD-related (political) dimensions, we look into the aggregated measures of each. The first, FD-related, group is an aggregation of the revenue sharing and revenue raising authority components, whereas the second, non-FD-related, group is an aggregation of the remaining ones. Regressions 10 and 11 present the results of the linear estimations of each of them. Here, the distinction is even clearer: the FD-related group has a significant negative association with oil rents, whereas the second group does not.

In addition, given the discrete nature of the Kearney Index, we test the above using probit estimation. More specifically, since the use of country-specific dummy variables is too demanding in the non-linear model, we exclude them from this specification. Instead, we follow the methodology set by Wooldridge (2005) and add various time-invariant controls to address the fixed-effects issue. These controls are the following: land area, latitude, legal origin, ethnic fractionalization, and the mean values of all time-variant independent variables. Marginal effects are reported in Columns 12 and 13, for the FD-related and non-FD-related groups, respectively. Results indicate that the negative effect is sourced solely in the FD-related dimensions, consistent with the outcome observed in the linear cases, thus motivating our focus on FD in the analysis presented in the following subsection.

\subsection{Fiscal decentralization}

Our next task is to dig deeper into the effects of resource booms on the level of FD. Following the earlier discussion, we concentrate initially on the Revenue Raising Authority dimension. This dimension measures the subnational governments' formal authority to raise their own revenue through taxation. Hence, from the two fiscally-related dimensions this one is more consistent with the model's notion of decentralization, motivating our choice of it. ${ }^{17}$ Results are presented in Table 2 .

We start by estimating Equation (23) using OLS. Keeping exposition to the minimum, we discuss only the main coefficients of interest, though nonetheless we note that results on all other

\footnotetext{
${ }^{17}$ Nonetheless, we note that results do not change qualitatively if instead we employ the Revenue Sharing dimension, an average of the two fiscally-related dimensions, or the overall index.
} 
controls are consistent with those reported in previous studies (with some sensitivity in significance to certain specifications). The basic result appears in Regression 1. As reported previously, the coefficient on the resource share proxy is negative and significant, confirming the main hypothesis oil booms decrease the level of FD. In terms of magnitudes, the result indicates that a one standard deviation increase in the GDP share of oil rents is associated with a decrease of one fifth of a standard deviation in the level of FD. ${ }^{18}$

Since FD is regarded as being relatively persistent, we add its level at $t-1$ as an additional explanatory variable in Regression 2. As expected, its coefficient is positive and significant providing some indication to the hypothesized persistence. Nevertheless, the coefficient on the resource share proxy remains negative, significant and similar in magnitude, showing that our main result also holds under this dynamic setting.

In Regression 3, we investigate the hypothesis of having U-shaped effects. As the anecdotes discussed initially imply, the relationship may not be linear: while FD can drop initially, it may increase if the level of oil rents becomes sufficiently large. To test this hypothesis, we add a squared term of our resource measure to the model. The coefficient on the squared term is indeed positive, but lack any statistical significance. This is consistent with the predictions of the model: given a decision not to secede, resource booms decrease the level of FD continuously, with no apparent U-shaped patterns.

Next, to be further consistent with the model, we look into the notion that regional demands matter when examining the resources-FD nexus. To test this, we employ the Override Authority component of the Kearney Decentralization Index. This dimension assesses whether the central government has the legal right to override the decisions and policies of lower levels of government; it is a dummy variable that can take a value of either 4 or 0 , with 4 representing the existence of such legal right. This measure enables us to control for CG's role, and interpret the main results as being triggered by RGs' perspective, at least to some extent. We add this measure, together with its interaction term with the resource share proxy, to the model. Results appear in Regression 4. The interaction term is negative and significant, consistent with the model: CG seeks full centralization, so that having a dominant one in a resource dependent economy provides a centralization-premium. Importantly, the coefficient on the resource share proxy remains negative and significant, suggesting FD is also an outcome of regional demands, consistent with the said hypothesis. We study further this cross country distinction in relative bargaining powers of $C G$ and $R G$, and its consistency with the model, in a later sub-section.

\footnotetext{
${ }^{18}$ Although not presented, if we employ as resource proxy the GDP share of rents from diffuse-source resources (agriculture, fishing, hunting, and forestry) at $t-1$, the estimated coefficient is non-significant. This strengthens the preference for focusing on oil-related resources.
} 
As before, due to the discrete nature of the Kearney index we undertake some probit estimations of Equation (23). We follow the same methodology described earlier, in Table 1, only here we also add the level of FD at the initial period (instead of its first lag) in the dynamic case, consistent with Wooldridge (2005). Results appear in Regressions 5-8, which are essentially the probit-version of Regressions 1-4. The reported marginal effects indicate that the main result holds: resource booms decrease the level of FD, even under the dynamic setting, present no U-shaped effects, and may be an outcome of regional demands.

\subsection{Mechanisms}

The model points at potential mechanisms for the negative effect of resource discoveries on FD, distinguished by the incentives of $\mathrm{CG}$ and RG and their relative bargaining power; specifically, $\mathrm{CG}$ may have direct access to the resource rents thereby increasing its income, whereas RG may have an incentive to redistribute some of the rents to share the risk involved. Nonetheless, we can think of other potential channels associated with the ultimate source of the observed outcome, such as institutional change, ethnic fractionalization, capacity of the region to make decisions, outcome of a violent environment, or the degree of openness. Since institutional quality is already controlled for in all specifications, and ethnic fractionalization is included in the probit cases, we test each of the other potential mechanisms. Results from this exercise are presented in the last five regressions of Table 2 .

Starting with openness, Alesina and Spolaore (1997) argue that increased economic integration leads to secession. Therefore, it could be that the underlying mechanism works through this channel. To test this we add a standard measure of trade openness to the model: the GDP share of trade. The result in Regression 9 refutes this hypothesis to some extent. As can be seen, the main coefficient of interest remains negative and significant, thus implying the mechanism at work is different. ${ }^{19}$

A second option is that the changes in FD are an outcome of violent political acts. The connection between resource booms and violent conflicts has been discussed extensively in the literature; ${ }^{20}$ hence, resource booms may affect FD through that channel. This may be especially applicable in economies with weak institutions. We test this hypothesis in Regression 10 by controlling for internal armed conflicts. Thus, based on data from the Uppsala Conflict Data Program, we add an indicator for whether an internal armed conflict has taken place in the investigated time period.

\footnotetext{
${ }^{19}$ Note that the coefficient on openness is negative and weakly significant, which although points at an opposite direction to that proposed by Alesina and Spolaore (1997), is consistent with findings of other studies on FD (e.g. Letelier (2005)).

${ }^{20}$ See, for instance, Brunnschweiler and Bulte (2009).
} 
The negative and significant coefficient on the resource share proxy implies that the changes in FD are not a consequence of this.

Third, we test the hypothesis that the result is driven by a simple mechanical outcome where CG appropriates RG's resource rents to itself. Put differently, it may be the case that regional governments follow the will of the central one because the latter has the legal right to enforce it; in effect, this is an additional test for whether regional demands indeed matter, as emphasized by the model. To look into that we run a version of Regression 4, only with the interaction term excluded; i.e. we add to the model the Override Authority measure discussed above. Results appear in Regression 11. Again, the coefficient on the resource share proxy remains negative and significant, implying this is not the underlying effect. We discuss this channel further in a later sub-section, where we test its relation to the risk sharing channel, as implied by the model.

Next, we test the effect of increasing risk. We attempt to capture the total effect of resources on risk through a proxy that measures the overall volatility in the economy. Following Poelhekke and Van der Ploeg (2009), volatility is measured by the standard deviation in the growth of real GDP per capita calculated over the intervals that we consider. Adding this measure in Regression 12 , we estimate a negative coefficient on the volatility proxy, consistent with the risk-heterogeneity trade-off put forward by the model. In addition, we see that once the risk component is controlled for, the effect of resources is an order of magnitude lower and is no longer statistically significant, providing evidence that the underlying mechanism may be one that pertains to the increasing risk involved with resource booms, and thus ultimately to the incentive to share risk. We note that although this result represents an average effect that applies to the sample as a whole, in a separate sub-section below we show this result is specific to, and driven by, the economies that have a relatively stronger $\mathrm{RG}$, as suggested by the model.

Last, we try to disentangle the effect of the two risk components: relative inefficiency, and revenue volatility. Data limitations do not allow us to test the dominance of each directly, but we can nevertheless attempt to do so indirectly. The abovementioned literature often indicates that local inefficiencies tend to be worse in economies with relatively weaker institutional quality, whereas the revenue volatility effect is triggered primarily by international shocks. Therefore, although institutional quality is already controlled for, if the local inefficiency effect is dominant, we can expect to see relatively more centralization in economies with weaker institutions. To test that, we add an interaction term of our institutional quality and resource measures (the latter at $t-1)$ in Regression 13. The lack of significance of the coefficient on this interaction term provides some indication that the key effect may be the one related to the revenue volatility. 


\subsection{Robustness checks}

So far, we used the GDP share of oil rents to capture the degree of resource abundance. We preferred this measure given its relatively wide use in the relevant literature. Nonetheless, this measure is potentially endogenous (see, for example, Van der Ploeg (2011)); to the extent that resource extraction is systematically associated with unobserved development factors, our results may suffer from an endogeneity bias. We address this concern by employing two additional resource proxies that are based on exogenous components of the output-based measure.

The first one relates to the discovery of giant oil fields, and is based on data provided by Horn (2011). A giant oil field is defined to be one for which the estimate of ultimately recoverable oil is at least 500 million bbl of oil or gas equivalent. Horn (2011) reports total ultimately recoverable bbl of oil and gas equivalent estimated at the time of discovery for all giant oil fields discovered from 1868 to 2011; we employ these data but focus on the giant oil fields discovered during our sample's time interval. Compared to oil rents, the new measure is more exogenous for two reasons. First, giant oil fields present potential for making significant amount of profits, which in turn attract even more interest by large multinational firms, making extraction-related activities independent of the local economy. Second, this measure provides the stock of potentially extractable oil, as opposed to the flow of rents. ${ }^{21}$

The second alternative looks into the variation in the international real price of oil. Changes in output-based measures may be driven by factors such as resource discoveries, extraction technology, and prices. The first two are potentially endogenous, whereas under reasonable assumptions the latter can be regarded as exogenous because oil prices are determined in the international market. We then build a proxy that exploits this exogenous variation in the international price of crude oil.

The measure is constructed as follows: for each country, we take the GDP share of oil rents in the earliest year available and multiply it by the average international real price of crude oil at time $t$. Thus, we keep the share of oil rents in GDP constant, and weigh it using oil prices that give the required variation. Figure 2 shows that the relative international ranking in the GDP share of oil rents has changed little over time; countries that were largely oil rich at the beginning of the period (1965) appear to hold their relative ranking 30 years later, with a correlation of 0.85 . Keeping the share of oil rents in GDP constant, hence, can still capture accurately the countries' relative position with respect to their resource abundance over time. Hence, to the extent that changes in international oil prices are exogenously driven and that initial oil output is pre-determined, we argue that the variation we investigate is indeed exogenous since it is entirely triggered by changes

\footnotetext{
${ }^{21}$ In effect, we follow the approach of Lei and Michaels (2014) who look into the effects of giant oil fields on internal armed conflicts, by arguing for the relative exogeneity of the former based on similar reasoning.
} 
in the international price of oil.

Table 3 provides results using these two additional variables. More specifically, Regressions 1 to 5 and 6 to 10 show estimated coefficients for the effect of natural resources on the level of FD using giant oil fields and the price-based measure, respectively. In both cases, results are qualitatively identical to the ones obtained in Regressions 1 and 9 to 12 of Table 2. The coefficient on the resource measure is negative and significant, making the main result robust to the new proxies. As before, the exceptions occur when we include the volatility measure. Consistent with the baseline analysis, Regressions 5 and 10 in Table 3 show that the risk sharing proxy is negative and significant, while natural resources are not. This provides additional evidence that resource windfalls affect FD through the risk channel. Nonetheless, as with the benchmark results, here as well we emphasize this represents the average result across our sample; below we look into the differential effects across levels of relative CG strength.

Next, we test the main hypothesis using a different FD measure. We follow Davoodi and Zou (1998), Oates (1985), and Zhang and Zou (1998), and employ the World Bank's Fiscal Decentralization Indicators, which are based on data from the International Monetary Fund's Government Finance Statistics. From the several alternatives provided by the World Bank, we pick Vertical Imbalance, which is the one that most closely resembles the model's notion of FD. This indicator measures the degree to which subnational governments fund their expenditures through their own revenue sources, and is a number between 0 and 100. A higher value means more independent subnational governments in terms of relying on their own revenue sources for their expenditures, implying that the country as a whole is more fiscally decentralized. The sample under the new variable covers the period of 1972-2000 and includes 78 countries. Given that observations are not available for all years and countries, we employ an unbalanced panel and 4-year time intervals to maximize coverage.

All other variables included in the regressions are identical to those used in the initial specifications (Tables 1-3), with the exception of being adjusted in terms of time intervals. Results are reported in Table 4. Regressions 1 to 4 again show a negative and significant impact of the resource share proxy that works primarily through the increased-risk mechanism.

Finally, we address two additional points. The first relates to the different underlying channel across levels of relative CG strength; the second discusses some potential sample selection concerns. Starting with the first, the model suggests that the risk sharing channel would be at work in economies with relatively stronger RGs, yet would not be accounted for in those with a more dominant CG. This, in turn, implies that the observed results on volatility, presented as an average across the whole sample, is entirely driven by the former type of economies, and should bear no 
effect in those of the latter type.

To test this, we split the sample to two groups, based on the level of relative CG strength. While the division can be based on the Override Authority measure discussed earlier, we base it on the cumulative score of the political dimensions, as in Regressions 11 and 13 of Table 1, to exploit further potential cross country variation. ${ }^{22}$ The division is based on the 50th-percentile score; being above (below) it is regarded as having a relatively stronger RG (CG). ${ }^{23}$ Other, more restrictive, divisions yield similar results, yet this one makes a relatively more equal division that we find appropriate for addressing sample selection concerns. Thus, the relevant cases for the risk sharing mechanism proposed, namely those in which RG has more significant bargaining power, have a wide coverage of both developing and developed economies. ${ }^{24}$ In fact, these relevant cases span over the vast majority of the countries in our sample, suggesting the risk sharing channel may not necessarily be a feature of a small subset. Importantly, given the smaller sample sizes tested, we mainly look for differences in coefficient magnitudes between the two groups.

Results appear in Regressions 1-5 of Table 5. Regressions 1-3 replicate the benchmark specification, as in Regression 1 of Table 2. The first uses the whole sample, and simply adds volatility to the baseline specification. This is similar to Regression 12 of Table 2, only without the various additional channels, indicating that the effect of volatility is not specific to the specification used; it is apparent regardless of the other channels. In Regressions 2 and 3, however, we estimate the same specification with volatility, under the divided samples. Through the significant differences in the magnitudes on our coefficient of interest, it can be seen that the risk sharing channel is at work only in the subsample in which RG is relatively stronger (Regression 3); conversely, when CG is relatively stronger resource booms continue to decrease FD regardless of volatility. This provides some support to the model which suggests that risk sharing is applicable in cases where RG has some significant bargaining power, whereas in those in which CG is stronger FD is decreased irrespective of risk.

To observe this more clearly, Regressions 4 and 5 replicate 3 and 4, only volatility is excluded. Interestingly, we see that while the coefficient in the case of a strong CG remains largely the same, the one in the case of a strong RG significantly increases, to levels similar to those observed under a strong CG, while maintaining similar levels of standard errors to those in Regression 3. This

\footnotetext{
${ }^{22}$ Nonetheless, we note that basing the division on the Override Authority measure yields similar results.

${ }^{23}$ Given multiple median-valued observations the division is not equal; the strong RG (CG) group, thus, includes 101 (103) observations.

${ }^{24}$ The following is the list of countries that have at least one observation with an above 50th-percentile cumulative score of the political dimensions (i.e. relatively stronger RG, at time $t$ ): Argentina, Australia, Bangladesh, Brazil, Canada, Chile, China, Colombia, France, Germany, Hungary, Italy, Japan, Kenya, Korea, Malaysia, Mexico, Nepal, Netherlands, Pakistan, Peru, Philippines, Poland, Romania, Russia, South Africa, Spain, Thailand, UK, USA, Uganda, and Venezuela.
} 
further illustrates that the risk channel is at work only in cases where RG is relatively strong. ${ }^{25}$

Moving to the second point, we realize that the rather limited sample of 44 countries may raise sample selection concerns. We follow Arzaghi and Henderson (2005) for our baseline decentralization measure, which was constructed based on data availability. Assuming that data availability is positively associated with institutional quality, we next test the applicability of the main result to economies with relatively weaker institutions, to mitigate concerns related to potential biases caused by the countries not included in the sample.

As a first step we reexamine Regression 13 of Table 2; the statistically insignificant coefficient on the interaction term of oil and institutional quality suggests there are no systematic differences in the effects of resource booms on FD across levels of institutional quality. Economies with relatively weaker institutions should, thus, yield similar results to those observed under the general sample. To test that, we restrict our sample to the bottom $10 \%$ of institutional quality, which is the subsample that is expected to yield results that would most closely follow those in the set of countries not included. Results appear in Regressions 6 and 7 of Table 5, which replicate the baseline specification (Regression 1 of Table 2) using the restricted sample; the former uses the baseline panel under the Kearney Index, whereas the latter adopts the extended one under the World Bank's Vertical Imbalance measure. Albeit having a significantly smaller sample size under these restricted cases, both show the main result holds; resource booms decrease the level of FD even in economies with the relatively weakest institutions, thus addressing the initial point to some extent.

In addition, we note that the magnitude is higher in both cases compared to the baseline. Again, given the previously discussed result on the interaction term, we cannot infer that there is a systematically stronger effect under this restricted group. Nonetheless, estimating an outcome that exceeds the average effect implies that, if anything, the countries not included in the sample are expected to intensify the observed main impact, further relieving concerns related to sample selection.

\section{Conclusion}

Can resource booms unify nations? In light of previous theoretical work and various anecdotes, one might suspect the answer is an unequivocal no. This paper, however, presented a new and opposite perspective on this, through the case of FD. We provided empirical evidence indicating that resource booms tend to decrease the level of FD, without affecting political decentralization,

\footnotetext{
${ }^{25}$ The patterns observed in Regressions 1-5 are robust to including all other previously discussed additional controls.
} 
and showed the robustness of this to various measures of decentralization and resource abundance, as well as to different controls, estimation techniques, and time periods.

In addition, we offered a theory that rationalizes this counter-intuitive empirical finding through a model of endogenous FD. The framework builds on two simple notions: first, a trade-off between risk sharing and heterogeneity; and second, a positive association between resource dependence and risk. With these two ingredients combined, the model showed that both the central and regional governments have an incentive to increase centralization following a resource boom. While CG's main incentives to centralize is to reduce local officials' extractive behavior or otherwise simply to increase its own income, a result that is largely standard in the literature, the theory suggested that RG may have a similar incentive as well through its objective to share the risks generated by natural resource dependence with the rest of the nation.

In equilibrium, having some bargaining power, $\mathrm{RG}$ redistributes a positive amount of its resource rents in exchange for a reduction in the degree of risk involved. Empirical testing of various potential mechanisms implied that income volatility and, therefore, risk sharing is the primary channel that drives the negative impact of natural resources on FD in nations with relatively stronger RGs, as opposed to those with a relatively stronger CG where resource booms appear to decrease the level of FD irrespective of the risk level. This is consistent with the predictions of the model.

The main policy implication of our paper for resource rich economies, in which RGs have some bargaining power, is that general trends to fiscally decentralize, as well as regional secessionist demands, may not be justified on economic grounds once risk sharing is accounted for. For example, the increase in FD levels promised by the UK government to the Scottish during the independencereferendum campaign in 2014 is probably attributed more to cultural and ethnic differences than to the discovery of oil reserves in the North Sea during the 1960s and 1970s. Nonetheless, our results are confined to the specific sample of countries and periods investigated; further research is still needed to fully understand the forces behind the decentralization decision of governments and the creation of nations. 


\section{Appendix}

\section{A Data}

Tables 1, 2, 3, and 5 (Regressions 1-6) employ a panel that covers the period of 1970-1995 in 5-year intervals; Tables 4 and 5 (Regression 7) employs a panel that covers the period of 1972-2008 with 4year intervals. Thus, variables correspond to those periods and time intervals in either case. Unless stated otherwise, variables are measured in the initial year of the corresponding time interval.

Variable definitions

Kearney Decentralization Index: Measures decentralization through an average of nine dimensions. Source: Arzaghi and Henderson (2005).

(i) Government Structure: Describes whether a country has a federal constitution; measured as either 0 or 4 , with 4 representing federal constitution.

(ii) Selection of Regional Executive: Measures whether a country's regional executives are elected; measured as either 0 or 4 , where 4 means they are elected (note that 'regional' refers to states or provinces).

(iii) Selection of Local Executive: Measures whether a country's local executives are elected; measured as either 0 or 4 , where 4 means they are elected (note that 'local' refers to municipalities or their functional equivalents).

(iv) Override Authority: Measures whether the central government has the legal right to override the decisions and policies of lower levels of government; measured as either 0 or 4 , where 4 means the existence of such legal right.

(v) Revenue Raising Authority: Describes sub-national governments' formal authority to raise their own revenue through taxation; measured as either 0,2 , or 4 , where 4 represents having the highest level of revenue raising autonomy and 0 the least.

(vi) Revenue Sharing: Describes whether a country's central government regularly and unconditionally transfers a portion of national taxes to lower levels of government; measured as either 0,2 , or 4 , where 4 represents having the highest level of revenue sharing and 0 the least.

(vii) Authority for Education: Measures responsibility for local primary education; measured as a number between 0 and 4, where 4 represents having the highest local responsibility and 0 the least.

(viii) Authority for Infrastructure: Measures responsibility over local highway construction; ; measured as a number between 0 and 4, where 4 represents having the highest local responsibility and 0 the least.

(ix) Authority for Police: Measures responsibility for local policing; ; measured as a number between 0 and 3, where 3 represents having the highest local responsibility and 0 the least.

GDP share of oil rents: GDP share of oil rents, expressed as a number between 0 and 1 . Rents are computed as unit rents times production, where a unit rent is defined as unit price minus unit cost. Source: World Bank Development Indicators (e.g., see World Bank 2011).

Price-based oil measure: GDP share of oil rents in initial year multiplied by the average international price of oil in time $\mathrm{t}$ (in thousands of real US\$). Rents are computed as unit rents times production, where a unit rent is defined as unit price minus unit cost. Source: World Bank Development Indicators.

Institutional quality: Political Rights Index, expressed as a number between one and seven, one presenting best institutional quality and seven least. Source: Freedom House.

Real per capita GDP: Real GDP per capita, in constant 2000 US\$ prices. Source: World Bank Development Indicators.

Population: Total population. Source: World Bank Development Indicators.

Openness: GDP share of trade. Source: World Bank Development Indicators. 
Urbanization: Share of urban population out of total population, expressed as a number between 0 and 100. Source: World Bank Development Indicators.

Internal armed conflicts: An indicator for whether an internal armed conflict has taken place in the investigated time interval. An internal armed conflict is defined as a contested incompatibility that concerns government and/or territory where the use of armed force between two parties, of which at least one is the government of a state, results in at least 25 battle-related deaths. More specifically, an internal armed conflict occurs between the government of a state and one or more internal opposition group(s) without intervention from other states. Source: Uppsala Conflict Data Program.

Giant oil fields: The logarithm of total recoverable bbl of oil and gas equivalent (estimated at the time of discovery) of all giant oil fields discovered in the investigated time period. A giant oil field is defined to be one for which the estimate of ultimately recoverable oil is at least 500 million bbl of oil or gas equivalent. Source: Horn (2011).

Vertical imbalance: : The extent to which sub-national governments rely on their own revenue sources for their expenditures, expressed as a number between 0 and 100. Source: World Bank Fiscal Decentralization Indicators.

Land area: Land area in square KM. Source: World Bank Development Indicators.

Latitude: The absolute value of the latitude of the capital city, divided by 90 (to take values between 0 and 1). Source: La Porta et al. (1999).

Legal Origin: Identifies the legal origin of the company law or commercial code for each country. There are four possible origins: 1) English common law; 2) French commercial code; 3) Socialist/Communist Laws; 4) German commercial code. Source: La Porta et al. (1999).

Ethnic Fractionalization: Reflects probability that two randomly selected people from a given country will not belong to the same ethno linguistic group. The higher the number the more fractionalized the society. Source: Alesina et al. (2003).

Volatility: The standard deviation of yearly GDP per capita growth in the 5 preceding years (to the year inspected). Source: World Bank Development Indicators.

\section{Countries included in sample}

Tables 1, 2, 3, and 5 (Regression 1): Algeria, Argentina, Australia, Bangladesh, Brazil, Cameroon, Canada, Chile, China, Colombia, Ecuador, Egypt, France, Germany, Ghana, Greece, Hungary, India, Indonesia, Italy, Japan, Kenya, Korea, Malaysia, Mexico, Mozambique, Nepal, Netherlands, Pakistan, Peru, Philippines, Poland, Romania, Russian Federation, South Africa, Spain, Sri Lanka, Syria, Thailand, Turkey, U.K., U.S., Uganda, Venezuela.

Table 4: Albania, Australia, Austria, Azerbaijan, Bahrain, Belarus, Belgium, Bolivia, Brazil, Bulgaria, Canada, Chile, China, Colombia, Costa Rica, Croatia, Czech Republic, Denmark, Dominican Republic, Ecuador, Estonia, Fiji, Finland, France, Gambia, Germany, Greece, Guatemala, Honduras, Hungary, Iceland, India, Indonesia, Iran, Ireland, Israel, Italy, Kenya, Korea, Latvia, Lithuania, Malawi, Malaysia, Mauritius, Mexico, Moldova, Mongolia, Netherlands, New Zealand, Nicaragua, Norway, Panama, Papua New Guinea, Paraguay, Peru, Philippines, Poland, Portugal, Romania, Russia, Senegal, Slovak Republic, Slovenia, South Africa, Spain, Sri Lanka, Swaziland, Sweden, Switzerland, Thailand, Tunisia, U.K., U.S., Uruguay, Venezuela, Zambia, Zimbabwe.

Table 5 (Regressions 2 and 4): Algeria, Brazil, Cameroon, Chile, China, Colombia, Ecuador, Egypt, Ghana, Greece, Hungary, India, Indonesia, Kenya, Korea, Mozambique, Nepal, Peru, Philippines, Romania, South Africa, Spain, Sri Lanka, Syria, Thailand, Turkey, Uganda, Venezuela.

Table 5 (Regressions 3 and 5): Argentina, Australia, Bangladesh, Brazil, Canada, Chile, China, Colombia, France, Germany, Hungary, Italy, Japan, Kenya, Korea, Malaysia, Mexico, Nepal, Netherlands, Pakistan, Peru, Philippines, Poland, Romania, Russia, South Africa, Spain, Thailand, U.K., U.S., Uganda, Venezuela.

Table 5 (Regression 6): Algeria, Argentina, Cameroon, Chile, China, Ecuador, Egypt, Germany, Ghana, Hungary, Indonesia, Kenya, Mozambique, Nepal, Pakistan, Peru, Syria, Uganda. 
Table 5 (Regression 7): Azerbaijan, Bahrain, Belarus, Bulgaria, Chile, China, Guatemala, Hungary, India, Indonesia, Iran, Kenya, Korea, Malawi, Malaysia, Mauritius, Panama, Paraguay, Peru, Russia, South Africa, Swaziland, Thailand, Tunisia, Uruguay, Zambia, Zimbabwe. 


\section{References}

[1] Alesina, A., Devleeschauwer, A., Easterly, W., Kurlat, S., and Wacziarg, R., 2003. Fractionalization. Journal of Economic Growth, 8, pp. 155-194.

[2] Alesina, A., and Spolaore, E., 1997. On the Number and Size of Nations. Quarterly Journal of Economics, 112(4), pp. 1027-1056.

[3] Alesina, A., and Spolaore, E., 2005. The Size of Nations. The MIT Press, Cambridge, MA, U.S.

[4] Araujo, M.C., Ferreira, F.H.G., Lanjouw, P., and Özler, B., 2008. Local Inequality and Project Choice: Theory and Evidence from Ecuador. Journal of Public Economics, 92(5), pp. 10221046 .

[5] Arzaghi, M., and Henderson, J., 2005. Why Countries Are Fiscally Decentralizing? Journal of Public Economics, 89, pp. 1157-1199.

[6] Bardhan, P., 2002. Decentralization of Governance and Development. Journal of Economic Perspectives, 16(4), pp. 185-205.

[7] Bardhan, P., and Mookherjee, D., 2000. Capture and Governance at the Local and National levels. American Economic Review Papers and Proceedings, 90(2), pp. 135-139.

[8] Beine, M., Coulombe, S., and Vermeulen, W., 2014. Dutch Disease and the Mitigation Effect of Migration: Evidence from Canadian Provinces. Economic Journal, forthcoming.

[9] Blattman, C., Hwang, J., and Williamson, J.G., 2007. Winners and Losers in the Commodity Lottery: The Impact of Terms of Trade Growth and Volatility in the Periphery 1870-1939. Journal of Development Economics, 82, pp. 156-179.

[10] Blattman, C., and Miguel, E., 2010. Civil War. Journal of Economic Literature, 48(1), pp. $3-57$.

[11] Boadway, R., 2006. Natural Resource Shocks and the Federal System: Boon and Curse? Fiscal Federalism and the Future of Canada Conference Proceedings, Institute of Intergovernmental Relations.

[12] Bolton, P., and Roland, G., 1997. The Breakup of Nations: A Political Economy Analysis. Quarterly Journal of Economics, 112(4), pp. 1057-90.

[13] Brennan, G., and Buchanan, J., 1980. The Power to Tax: Analytical Foundations of a Fiscal Constitution. Cambridge University Press, NY, U.S.

[14] Brollo, F., Nannicini, T., Perotti, R., and Tabellini, G., 2012. The Political Resource Curse. American Economic Review, 103(5), pp. 1759-96.

[15] Brosio, G., 2006. The Assignment of Revenue from Natural Resources. Chaper 17 in Handbook of Fiscal Federalism, edited by Ehtisham Ahmad and Giorgio Brosio. Edward Elgar Publisher, Northampton, MA, U.S.

[16] Brunnschweiler, N.C., and Bulte, H.E., 2009. Natural Resources and Violent Conflict: Resource Abundance, Dependence and the Onset of Civil Wars. Oxford Economic Papers, 61(4), pp. 651-674. 
[17] Buchanan, J.M., and Faith, R.L., 1987. Secession and the Limits of Taxation: Toward a Theory of Internal Exit. American Economic Review, 77, pp.1023-31.

[18] Cai, T., and Treisman, D., 2005. Does Competition for Capital Discipline Governments? Decentralization, Globalization, and Public Policy. American Economic Review, 95, pp. 817-830.

[19] Campante, F.R., and Do, Q., 2014. Isolated Capital Cities, Accountability, and Corruption: Evidence from U.S. States. American Economic Review, 104, pp. 2456-2481.

[20] Caselli, F., Michaels, G., 2013. Do Oil Windfalls Improve Living Standards? Evidence from Brazil. American Economic Journal: Applied Economics, 5(1), pp. 208-38.

[21] Davis, J., Ossowski, R., Daniel, J., and Barnett, S., 2001. Stabilization and Savings Funds for Nonrenewable Resources: Experience and Fiscal Policy Implications. IMF Ocassional Paper 205.

[22] Davoodi, H., and Zou,. H., 1998. Fiscal Decentralization and Economic Growth: A Cross Country Study. Journal of Urban Economics, 43, pp. 244-257.

[23] Duek, A., and Rusli, R., 2010. The Natural Resources Industry in Decentralized Indonesia: How Has Decentralization Impacted the Mining, Oil and Gas Industries. CREA Discussion Paper 2010-5, University of Luxembourg.

[24] Fisman, R., and Gatti, R., 2002. Decentralization and Corruption: Evidence from U.S. Federal Transfer Programs. Public Choice, 113, pp. 25-35.

[25] Freinkman, L., and Plekhanov, A., 2009. Fiscal Decentralization in Rentier Regions: Evidence from Russia. World Development, 37(2), pp. 503-512.

[26] Galasso, E., and Ravallion, M., 2005. Decentralized Targeting of an Antipoverty Program. Journal of Public Economics, 89(4), pp. 705-727.

[27] Glaeser, E.L., and Saks, R.E., 2006. Corruption in America. Journal of Public Economics, 90, pp.1053-1052.

[28] Goldsmith, A.A., 1999. Slapping the Grasping Hand: Correlates of Political Corruption in Emerging Markets. American Journal of Economics and Sociology, 58(4), pp. 866-883.

[29] Hatfield, J., W., and Miquel, P.G., 2012. A Political Economy Theory of Partial Decentralization. Journal of the European Economic Association, 10(3), pp. 605-633.

[30] Horn, M. K. (2011). Giant fields Data Set, Revision 16: AAPG - GIS Open file.

[31] Jia, R., and Nie, H., 2015. Decentralization, Collusion and Coalmine Deaths. Review of Economics and Statistics, forthcoming.

[32] La Porta, R., Lopez-de-Silanes, F., Shleifer, A., and Vishny, R., 1999. The Quality of Government. Journal of Law, Economics and Organization, 15(1), pp. 222-279.

[33] Lei, Y., and Michaels, G., 2014. Do Giant Oilfield Discoveries Fuel Internal Armed Conflicts? Journal of Development Economics, 110, pp. 139-157.

[34] Lambsdorff, J.G., 2006. Causes and Consequences of Corruption: What Do We Know from a Cross-Section of Countries? In International Handbook on the Economics of Corruption, edited by Susan Rose-Ackerman, Chapter 1, Edward Elgar publishing. 
[35] Letelier, L.S., 2005. Explaining Fiscal Decentralization. Public Finance Review, 33, pp. 155-83.

[36] Mookherjee, D., 2015. Political Decentralization. Annual Review of Economics, 7, pp. 231-49.

[37] Oates, W., 1972. Fiscal Federalism. Harcourt Brace Jovanovich, Academic Press, NY, U.S.

[38] Oates, W., 1985. Searching For Leviathan: An Empirical Analysis. American Economic Review, 75 , pp. 748-757.

[39] Papyrakis, E., and Raveh, O., 2014. An Empirical Analysis of a Regional Dutch Disease: The Case of Canada. Environmental and Resource Economics, 58(2), pp. 179-198.

[40] Perez-Sebastian, F., and Raveh, O., 2015. The Natural Resource Curse and Fiscal Decentralization. American Journal of Agricultural Economics, forthcoming.

[41] Persson, T., and Tabellini, G., 1996a. Federal Fiscal Constitutions: Risk Sharing and Redistribution. Journal of Political Economy, 104(5), pp. 979-1009.

[42] Persson, T., and Tabellini, G., 1996b. Fiscal Constitutions: Risk Sharing and Moral Hazard. Econometrica, 64(3), pp. 623-646.

[43] Panizza, U., 1999. On the Determinants of Fiscal Centralization: Theory and Evidence. Journal of Public Economics, 74, pp. 97-139.

[44] Poelhekke, S., and Van der Ploeg, F., 2009. Volatility and The Natural Resource Curse. Oxford Economic Papers, 61(4), pp. 727-760.

[45] Poelhekke, S., and Van der Ploeg, F., 2010. The Pungent Smell of "Red Herrings": Subsoil Assets, Rents, Volatility, and the Resource Curse. Journal of Environmental Economics and Management, 60, pp. 44-55.

[46] Prud'homme, R. 1995. The Dangers of Decentralization. The World Bank Research Observer, 10(2), pp. 201-220.

[47] Raveh, O., 2013. Dutch Disease, Factor Mobility, and the Alberta Effect - The Case of Federations. Canadian Journal of Economics, 46(4), pp. 1317-1350.

[48] Ross, M.L., 2004. What Do We Know about Natural Resources and Civil War? Journal of Peace Research, 41(3), pp. 337-56.

[49] Ross, M.L., 2006. A Closer Look at Oil, Diamonds, and Civil War. Annual Review of Political Science, 9, pp. 265-300.

[50] Seabright, P., 1996. Accountability and Decentralization in Government: An Incomplete Contracts Model. European Economic Review, 40(1), pp. 61-89.

[51] Stroebel, J., and van Benthem, A., 2013. Resource Extraction Contracts Under Threat of Expropriation: Theory and Evidence. Review of Economics and Statistics, 95(5), pp. 16221639.

[52] Treisman, D., 2000. The Causes of Corruption: A Cross National Study. Journal of Public Economics, 76(3), pp. 399-457.

[53] Treisman, D., 2006. Explaining Fiscal Decentralization: Geography, Colonial History, Economic Development, and Political Institutions. Journal of Commonwealth and Comparative Politics, 44(3). 
[54] Van den Bremer, T.S., and Van der Ploeg, F., 2013. Managing and Harnessing Volatile Oil Windfalls. IMF Economic Review, 61(1), pp. 130-167.

[55] Van der ploeg, F., 2010. Aggressive Oil Extraction and Precautionary Saving: Coping with Volatility. Journal of Public Economics, 94, pp. 421-433.

[56] Van der ploeg, F., 2011. Natural Resources: Curse or Blessing? Journal of Economic Literature, 49(2), pp. 366-420.

[57] Wilson, J.Q., 1966. Corruption: The Shame of the States. Public Politics, 2, pp. 28-38.

[58] Wooldridge, M.J., 2005. Simple Solutions to the Initial Conditions Problem in Dynamic, Nonlinear Panel Data Model with Unobserved Heterogeneity. Journal of Applied Econometrics, 20(1), pp. 39-54.

[59] World Bank, 2011. World Development Indicators. The World Bank, Washington D.C, U.S.

[60] Zhang, T., and Zou, H., 1998. Fiscal Decentralization, Public Spending, and Economic Growth. Journal of Public Economics, 67, pp. 221-240. 